\title{
Cytogenetical Effects of Chemical Mutagens in Rice
}

\author{
T. V. V. Seetharami Reddi and V. R. Reddi \\ Department of Botany, Andhra University, \\ Waltair 530003 , India
}

Accepted February 13, 1984

The volume of work carried out with chemical mutagens is comparatively less. Progress in the effective and efficient use of chemicals is hindered by complex interplay of many physical and chemical factors that determine the ultimate yield of mutations (Konzak et al. 1964). The degree of cytological aberrations either in mitosis or meiosis is regarded as one of the dependable criteria for estimating the effect of a mutagen. A variety of nuclear and nucleolar anomalies in meiosis has been reported in mutagen treated rice by several workers (Parthasarathy 1938, Oka et al. 1952, Nishimura 1957, Hsieh 1961, Chao and Chai 1961, Katayama 1963, Siddiq 1973, Reddi and Reddi 1975, Seetharami Reddi 1977 and Ramesh 1983). The present study is undertaken to obtain information of four chemicals in inducing chromosomal aberrations in three rice cultivars.

\section{Materials and methods}

Five hundred normal seeds of each of the three rice cultivars viz: T(N)1, IR 8 and Sona with $14 \%$ moisture content, presoaked for $12 \mathrm{~h}$ in distilled water were treated with chemical mutagens, methyl methane sulphonate (MMS), dimethyl sulphate (DMS), dichloroethyl methane sulphonate (DEMS) and diethylsulphate (dES) at $28 \pm 1^{\circ} \mathrm{C}$. The concentrations used were $0.03,0.05$ and 0.1 per cent by volume except in the case of DEMS in which $0.05,0.1$ and 0.2 were used. In view of the short half-life of dES, the solution was replenished for every $30 \mathrm{~min}$. The seeds were continuously shaken in the mutagen solutions throughout the $12 \mathrm{~h}$ period of treatment. As a post-treatment care, the seeds were washed in running water for $60 \mathrm{~min}$, allowed to recover in fresh water for $3 \mathrm{~h}$ and sown directly in seed beds along with untreated controls. Material for cytological examination was collected from individual plants. Fixation of panicles of suitable stage for meiotic study was done at $14^{\circ} \mathrm{C}$ for $24 \mathrm{~h}$ in acetic alcohol (1:4) after which the material was transferred to $70 \%$ alcohol. Smear preparations of anthers were made in $1 \%$ acetocarmine.

\section{Results}

i. Frequency of aberrations: In $\mathrm{T}(\mathrm{N}) 1$ cytologically abnormal plants were detected in all the mutagenic treatments. In DMS the frequency of aberrant plants decreased with increase in dose whereas in dES a linear relationship was noticed (Table 1). In IR 8 only eight aberrant plants were observed in 0.03 and 0.1 DMS and 0.05 DEMS treatments. On the other hand, Sona responded positively. In 
DMS 0.1 and dES $0.03,40 \%$ abnormality in each was observed. No abnormal plants were observed in MMS and DMS 0.05 treatments.

Table 1. Frequency of cytologically aberrant plants in $\mathbf{M}_{1}$

\begin{tabular}{|c|c|c|c|c|c|c|c|c|c|c|}
\hline \multirow[b]{2}{*}{ Mutagen } & \multirow[b]{2}{*}{ Dose } & \multicolumn{3}{|c|}{$\mathbf{T}(\mathbf{N}) 1$} & \multicolumn{3}{|c|}{ IR 8} & \multicolumn{3}{|c|}{ SONA } \\
\hline & & $\begin{array}{l}\text { Total } \\
\text { plants } \\
\text { screen- } \\
\text { ed }\end{array}$ & $\begin{array}{l}\text { No. ab- } \\
\text { normal }\end{array}$ & $\%$ & $\begin{array}{l}\text { Total } \\
\text { plants } \\
\text { screen- } \\
\text { ed }\end{array}$ & $\begin{array}{l}\text { No. ab- } \\
\text { normal }\end{array}$ & $\%$ & $\begin{array}{c}\text { Total } \\
\text { plants } \\
\text { screen- } \\
\text { ed }\end{array}$ & $\begin{array}{l}\text { No. ab- } \\
\text { normal }\end{array}$ & $\%$ \\
\hline Control & & 19 & - & - & 21 & - & - & 20 & - & - \\
\hline \multirow[t]{3}{*}{ MMS } & 0.03 & 44 & 6 & 13.6 & 29 & - & - & 10 & - & - \\
\hline & 0.05 & 40 & 2 & 5.0 & 8 & - & - & 6 & - & - \\
\hline & 0.1 & 12 & 4 & 33.3 & 11 & - & - & - & - & - \\
\hline \multirow[t]{3}{*}{ DMS } & 0.03 & 22 & 10 & 45.4 & 8 & 2 & 25.0 & 12 & 2 & 16.6 \\
\hline & 0.05 & 12 & 4 & 33.3 & 8 & - & - & 6 & - & - \\
\hline & 0.1 & 18 & 4 & 22.2 & 12 & 4 & 33.3 & 10 & 4 & 40.0 \\
\hline \multirow[t]{3}{*}{ DEMS } & 0.05 & 16 & 6 & 37.5 & 10 & 2 & 20.0 & 12 & 4 & 33.3 \\
\hline & 0.1 & 20 & 6 & 30.0 & 8 & - & - & 16 & 6 & 37.5 \\
\hline & 0.2 & 30 & 12 & 40.0 & 8 & - & - & 8 & 2 & 25.0 \\
\hline \multirow[t]{3}{*}{ dES } & 0.03 & 30 & 2 & 6.6 & 9 & - & - & 10 & 4 & 40.0 \\
\hline & 0.05 & 14 & 2 & 14.2 & 8 & - & - & 10 & 2 & 20.0 \\
\hline & 0.1 & 18 & 6 & 33.3 & 7 & - & - & 18 & 6 & 33.3 \\
\hline
\end{tabular}

Table 2. Variety-wise frequency of cytologically abnormal plants in $\mathbf{M}_{1}$

\begin{tabular}{lccc}
\hline Variety & Total plants & No. abnormal & $\%$ abnormality \\
\hline T(N)1 & 276 & 64 & 23.18 \\
IR 8 & 126 & 8 & 6.34 \\
Sona & 118 & 30 & 24.52 \\
\hline
\end{tabular}

Table 3. Combined frequencies of cytologically abnormal plants in the three varieties

\begin{tabular}{lccc}
\hline Mutagen & Total plants & No. abnormal & $\%$ of abnormal plants \\
\hline Control & 60 & - & - \\
MMS & 160 & 12 & 7.5 \\
DMS & 108 & 30 & 27.7 \\
DEMS & 128 & 38 & 29.6 \\
dES & 124 & 22 & 17.7 \\
\hline
\end{tabular}

When comparison was made by mutagen- and variety-wise, the highest frequency of aberrations was observed in DEMS in T(N)1 and Sona and DMS in IR 8. MMS treatments were ineffective in IR 8 and Sona. The frequency of aberrations induced in Sona was relatively more $(24.5 \%)$ followed by $T(N) 1(23.1 \%)$ and IR $8(6.3 \%)$ (Table 2$)$. When comparison was made with respect to mutagens alone on the three varieties put together DEMS showed highest aberration rate $(29.6 \%)$ followed by DMS (27.7\%), dES (17.7\%) and MMS (7.5\%) (Table 3).

Table 4 shows the percentage frequency of abnormalities recorded. They were classified broadly into i) budding of nucleoli, ii) persistent nucleolus, iii) bridges 
and iv) other types (laggards, more rod bivalents, more ring bivalents, multipolar spindles, univalents, delayed disjunctions, fragments and suspected translocation heterozygotes). In $\mathrm{T}(\mathrm{N}) 1$ nucleolar budding of $15.3 \%$ was observed in DMS followed by others. Persistent nucleolus at metaphase I, or anaphase I or telophase I showed highest frequency of $7.6 \%$ in DMS followed by dES, DEMS and MMS. Highest frequency of $9.0 \%$ bridges was found in DEMS followed by DMS and

Table 4. Frequency of cytological abnormalities

\begin{tabular}{|c|c|c|c|c|c|c|c|c|c|c|}
\hline \multirow{2}{*}{ Mutagen } & \multirow{2}{*}{$\begin{array}{c}\text { Nature of } \\
\text { abnormality }\end{array}$} & \multicolumn{3}{|c|}{$\mathrm{T}(\mathrm{N}) 1$} & \multicolumn{3}{|c|}{ IR 8} & \multicolumn{3}{|c|}{ SONA } \\
\hline & & $\begin{array}{c}\text { Total } \\
\text { no. }\end{array}$ & $\begin{array}{c}\text { Abnor- } \\
\text { mal }\end{array}$ & $\%$ & $\begin{array}{c}\text { Total } \\
\text { no. }\end{array}$ & $\begin{array}{c}\text { Abnor- } \\
\text { mal }\end{array}$ & $\%$ & $\begin{array}{l}\text { Total } \\
\text { no. }\end{array}$ & $\begin{array}{c}\text { Abnor- } \\
\text { mal }\end{array}$ & $\%$ \\
\hline Control & $\begin{array}{l}\text { Nucleolar } \\
\text { budding } \\
\text { Pers. nucleolus } \\
\text { Bridges } \\
\text { Other types }\end{array}$ & 20 & $\bar{z}$ & $\begin{array}{l}\bar{z} \\
\bar{z}\end{array}$ & 20 & $\begin{array}{l}= \\
=\end{array}$ & $\begin{array}{l}\bar{z} \\
=\end{array}$ & 21 & $\begin{array}{l}= \\
\bar{z}\end{array}$ & $=$ \\
\hline MMS & $\begin{array}{l}\text { Nucleolar } \\
\text { budding } \\
\text { Pers. nucleolus } \\
\text { Bridges } \\
\text { Other types }\end{array}$ & 48 & $\begin{array}{r}2 \\
1 \\
3 \\
-\end{array}$ & $\begin{array}{l}4.1 \\
2.0 \\
6.2 \\
-\end{array}$ & 55 & $\begin{array}{l}\bar{z} \\
z\end{array}$ & $\begin{array}{l}\bar{z} \\
\overline{-}\end{array}$ & 45 & $\begin{array}{l}\bar{z} \\
=\end{array}$ & $=$ \\
\hline DMS & $\begin{array}{l}\text { Nucleolar } \\
\text { budding } \\
\text { Pers. nucleolus } \\
\text { Bridges } \\
\text { Other types }\end{array}$ & 52 & $\begin{array}{l}8 \\
4 \\
4 \\
2\end{array}$ & $\begin{array}{r}15.3 \\
7.6 \\
7.6 \\
3.8\end{array}$ & 56 & $\begin{array}{r}8 \\
4 \\
-\end{array}$ & $\begin{array}{c}14.2 \\
7.1 \\
-\end{array}$ & 56 & $\frac{4}{4}$ & $\begin{array}{l}\frac{7.1}{7.1} \\
7.1\end{array}$ \\
\hline DEMS & $\begin{array}{l}\text { Nucleolar } \\
\text { budding } \\
\text { Pers. nucleolus } \\
\text { Bridges } \\
\text { Other types }\end{array}$ & 66 & $\begin{array}{r}6 \\
2 \\
6 \\
10\end{array}$ & $\begin{array}{r}9.0 \\
3.0 \\
9.0 \\
15.1\end{array}$ & 78 & $\begin{array}{l}6 \\
=\end{array}$ & $\begin{array}{l}7.6 \\
=\end{array}$ & 72 & $\frac{16}{4}$ & $\begin{array}{r}22.2 \\
5.5 \\
5.5\end{array}$ \\
\hline $\mathrm{dES}$ & $\begin{array}{l}\text { Nucleolar } \\
\text { budding } \\
\text { Pers. nucleolus } \\
\text { Bridges } \\
\text { Other types }\end{array}$ & 62 & $\begin{array}{r}4 \\
\frac{2}{4} \\
4\end{array}$ & $\begin{array}{l}6.4 \\
3.2 \\
6.4\end{array}$ & 44 & $\begin{array}{l}= \\
=\end{array}$ & $\begin{array}{l}= \\
\bar{z}\end{array}$ & 38 & $\frac{6}{\frac{6}{6}}$ & $\frac{15.7}{\frac{7}{15.7}}$ \\
\hline
\end{tabular}

MMS. The frequency of other types was $15.1 \%$ in DEMS followed by dES and DMS treatments. In IR 8, nucleolar budding and persistent nucleolus were seen in DMS and nucleolar budding only in DEMS. In Sona nucleolar budding was highest in DEMS $(22.2 \%)$ followed by dES and DMS. Bridges were seen in DMS and DEMS and other types in DMS, DEMS and dES treatments.

ii. Cytological observations: The most common type of abnormality noticed in the meiotic cells involved the nucleolus. The number of nucleoli varied from two to many. In the multinucleolate cells, the size of the nucleolus decreased gradually with an increase in their number. Multinucleolar condition was observed at diakinesis and persistent nucleolar bodies of varying sizes were also recorded at metaphase I (Fig. 1), anaphase I, telophase I (Fig. 5), interkinesis and even during the second division of meiosis. Other abnormalities include lagging chromosomes at anaphase II (Fig. 6), bridges with or without fragments (Figs. 2, 4 and 7) and delayed separation at anaphase I (Fig. 3). Bridges appeared even at 
anaphase II in DEMS 0.2 of $\mathrm{T}(\mathrm{N}) 1$. At pachytene one or more chromosomes of individual cells showed detectable structural alterations. Unpaired or loosely paired regions, buckle formations suggesting deletions or duplications were relatively more common. Although interchanges were observed in DEMS 0.05 of Sona at a lower frequency in PMCs at diakinesis they could not be established as such at pachytene stage of mieosis.

\section{Discussion}

Although it is known that physical agents are most potent in inducing chromosome breaks when compared to chemicals, increased rate of point mutations are often recorded with the latter. Kawai and Sato (1965) reported the effect of ethylene imine on rice was about five times as high as the corresponding effects of X-irradiation. Siddiq (1973) obtained higher frequency of translocations in $T(N) 1$ and Taichung 65 irradiated with physical agents when compared to treatments with EMS and NMU. Multinucleolate condition at diakinesis and persistent nucleoli at metaphase I, anaphase I, telophase I and even during the second division of meiosis are more commonly noticed in $\mathrm{T}(\mathrm{N}) 1$ and Sona than in IR 8 . Bridges without fragments are more common than those with bridge and fragment which is in agreement with the findings of Shastry and Ramiah (1961) and Siddiq (1973). In the present study, plants with interchanges are relatively few. Plants with single quadrivalent per PMC were recorded earlier by Shastry and Ramiah (1961) in rice variety NP 130 treated with physical mutagenes and ${ }^{35} \mathrm{~S}$. Chromosome bridges accompanied by fragments are less frequent than multivalents in all treatments. Pachytene analysis revealed small differential segments in all treatments as observed in the present study. Nucleolar anomalies such as multinucleolate cells and persistent nucleoli are of common occurrence in the mutagen treated population. Natarajan (1958) reported a similar phenomenon in maize following radiation treatment and Siddiq (1964) in colchicine treated Sorghum. Multinucleolate condition observed in the present study might be due to a particular genotypic change suppressing the organising capacity of nucleolar chromosome and induce the formation of adventitious nucleoli, as suggested by Mc Clintock (1934). Genotypic changes disrupting the orderly production and dispersion of RNA are evidently more common in the present study and are also reported earlier by Siddiq (1973). Other meiotic abnormalities such as cryptic alterations noted in the pachytene chromosomes, delayed separation and bridges and fragments at anaphase I and of higher incidence of rod bivalents and univalents indicates the kind of cytogenetic effects that chemicals of the present study are capable of inducing.

Figs. 1-7. 1, T(N)1, MMS 0.05 showing persistent nucleolus at metaphase $\mathrm{I} . \quad \times 1500.2, \mathrm{~T}(\mathrm{~N}) 1$, MMS 0.03 showing two bridges one with fragment and one without fragment at anaphase $\mathrm{I}$.

$\times 1500$. 3, T(N)1, MMS 0.03 showing delayed separation of chromosomes at anaphase $\mathrm{I} . \quad \times 1500$. 4, T(N)1, DMS 0.1 showing bridge with fragment on the midway at anaphase I. $\times 1500.5$, $\mathrm{T}(\mathrm{N}) 1$, DEMS 0.2 showing two buds of nucleoli in between, there is one laggard chromosome at anaphase I. $\times 1500.6, T(N) 1$, DEMS 0.2 showing laggards at anaphase $\mathrm{II} . \times 1500.7, T(N) 1$, MMS 0.03 showing bridge with fragment at anaphase II (bridge connection is in out of focus). 


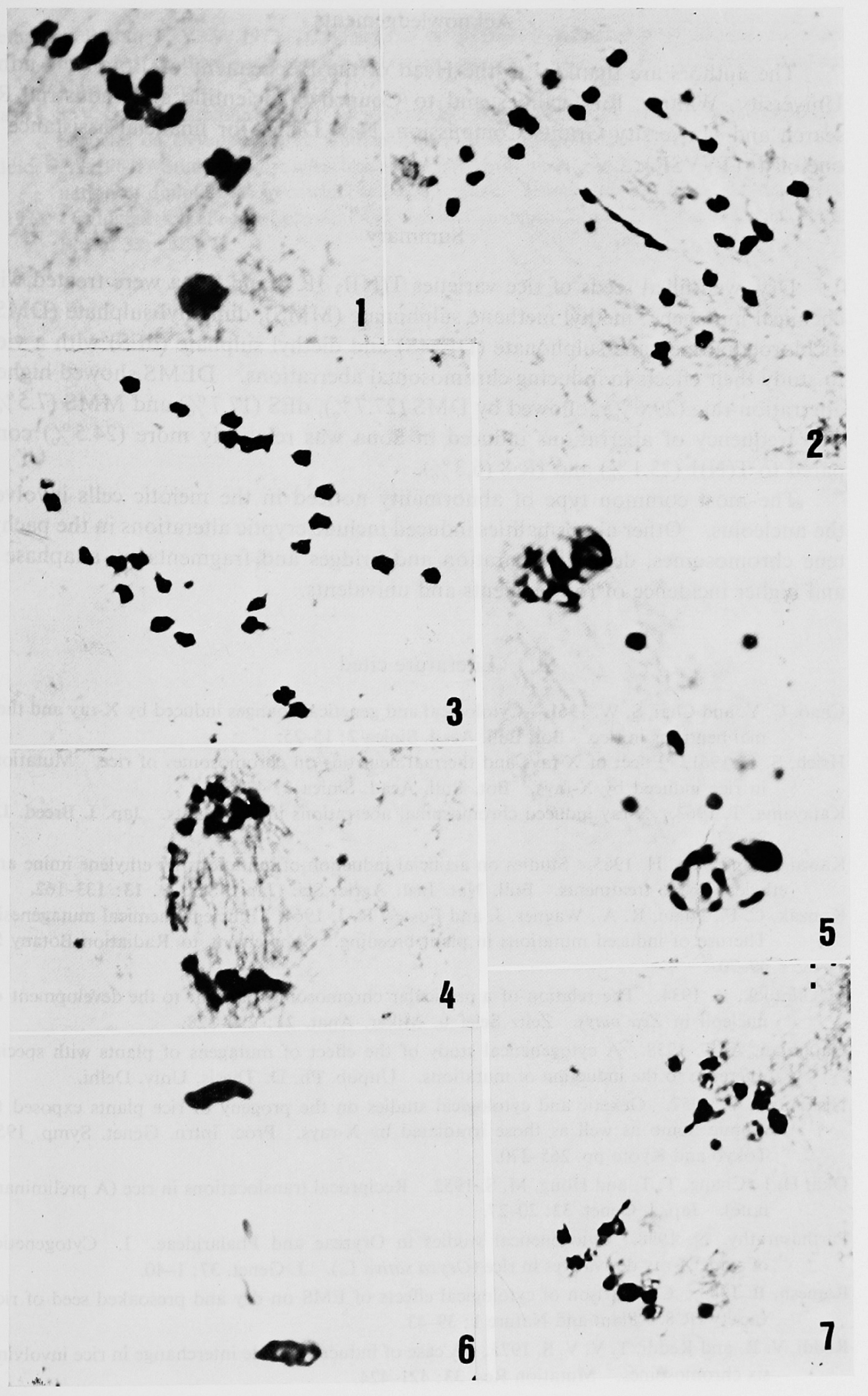




\section{Acknowledgements}

The authors are thankful to the Head of the Department of Botany, Andhra University, Waltair, for facilities and to Council of Scientific and Industrial Research and University Grants Commission, New Delhi, for financial assistance to one of us (TVVSR).

\section{Summary}

Dry, well filled seeds of rice varieties $T(N) 1$, IR 8 and Sona were treated with chemical mutagens: methyl methane sulphonate (MMS), dimethyl sulphate (DMS), dichloroethyl methane sulphonate (DEMS) and diethyl sulphate (dES) with a view to study their effects in inducing chromosomal aberrations. DEMS showed highest aberration rate $(29.6 \%)$ followed by DMS $(27.7 \%)$, dES $(17.7 \%)$ and MMS $(7.5 \%)$. The frequency of aberrations induced in Sona was relatively more $(24.5 \%)$ compared to $\mathrm{T}(\mathrm{N}) 1(23.1 \%)$ and IR $8(6.3 \%)$.

The most common type of abnormality noticed in the meiotic cells involved the nucleolus. Other abnormalities induced include cryptic alterations in the pachytene chromosomes, delayed separation and bridges and fragments at anaphase I and higher incidence of rod bivalents and univalents.

\section{Literature cited}

Chao, C. Y. and Chai, S. W. 1961. Cytological and genetical changes induced by X-ray and thermal neutrons in rice. Bot. Bull. Acad. Sinica 2: 15-25.

Hsieh, S. C. 1961. Effect of X-rays and thermal neutrons on chromosomes of rice. Mutations in rice induced by X-rays. Bot. Bull. Acad. Sinica 2: 43-50.

Katayama, T. 1963. X-ray induced chromosomal aberrations in rice plants. Jap. J. Breed. 13: 83-87.

Kawai, T. and Sato, H. 1965. Studies on artificial induction of mutations by ethylene imine and ethylene oxide treatments. Bull. Nat. Inst. Agric. Sci. (Jap.), Ser. D. 13: 133-162.

Konzak, C. F., Nilan, R. A., Wagner, J. and Foster, R. J. 1964. Efficient chemical mutagenesis. The use of induced mutations in plant breeding. Supplement to Radiation Botany 5: 49-70.

McClintock, B. 1934. The relation of a particular chromosomal element to the development of nucleoli in Zea mays. Zeitz Selef u. Miker. Anat. 21: 294-328.

Natarajan, A T. 1958. A cytogenetical study of the effect of mutagens of plants with special reference to the induction of mutations. Unpub. Ph. D. Thesis, Univ. Delhi.

Nishimura, Y. 1957. Genetic and cytological studies on the progeny of rice plants exposed to atomic bomb as well as those irradiated by X-rays. Proc. Intrn. Genet. Symp. 1956 Tokyo and Kyoto pp. 265-270.

Oka, H. I., Chang, T. T. and Hong, M. S. 1952. Reciprocal translocations in rice (A preliminary note). Jap. J. Genet. 32: 20-27.

Parthasarathy, N. 1938. Cytogenetical studies in Oryzeae and Phalarideae. I. Cytogenetics of some X-ray derivatives in rice (Oryza sativa L.). J. Genet. 37: 1-40.

Ramesh, B. 1983. Comparison of cytological effects of EMS on dry and presoaked seed of rice variety IR 8. Plant and Nature 1: 39-43.

Reddi, V. R. and Reddi, T. V. V. S. 1975. A case of induced double interchange in rice involving six chromosomes. Mutation Res. 33: 421-424. 
Seetharami Reddi, T. V. V. 1977. Cytogenetics of mutants induced by physical and chemical mutagens in three varieties of rice (Oryza sativa L.). Unpub. Ph. D. Thesis, Andhra Univ. Waltair.

Shastry, S. V. S. and Ramiah, K. 1961. Cytogenetical effects of X-rays, thermal neutrons and $\beta$ particles on Oryza sativa L. Indian J. Genet. Plant Breed. 21: 43-51.

Siddiq, E. A. 1964. Studies on the induction of polyploidy in maize and Sorghum and on the elimination of diploid cells in colchicine treated maize. Unpub. M. Sc. Thesis, IARI, Delhi.

- 1973. Cytogenetical effects of physical and chemical mutagens in rice. Indian J. Genet. Plant Breed. 33: 162-171. 